\title{
RNA interference-mediated targeting of urokinase plasminogen activator receptor and matrix metalloproteinase-9 gene expression in the IOMM-Lee malignant meningioma cell line inhibits tumor growth, tumor cell invasion and angiogenesis
}

\author{
PADMAJA TUMMALAPALLI ${ }^{1}$, CHRISTOPHER S. GONDI ${ }^{1}$, DZUNG H. DINH ${ }^{2}$, \\ MEENA GUJRATI ${ }^{3}$ and JASTI S. RAO ${ }^{1,2}$ \\ Departments of ${ }^{1}$ Cancer Biology and Pharmacology, ${ }^{2}$ Neurosurgery and ${ }^{3}$ Pathology, \\ University of Illinois College of Medicine at Peoria, Peoria, IL, USA
}

Received January 22, 2007; Accepted March 5, 2007

\begin{abstract}
Abstact. Meningiomas are the most commonly occurring tumors of the central nervous system including the brain and spinal cord. Malignant meningiomas are highly aggressive and frequently recur after surgical resection of the tumor. Our previous studies have reported that urokinase plasminogen activator receptor (uPAR) and matrix metalloproteinase-9 (MMP-9) play important roles in tumor progression. In the present study, we have attempted to evaluate the roles of these molecules in the malignant meningioma tumor microenvironment and to determine the effectiveness of using single or bicistronic small interfering RNA constructs for UPAR and MMP-9 on tumor cell proliferation, migration, invasion, angiogenesis and regression of pre-established orthotopic tumors. Transfection of single or bicistronic constructs downregulated UPAR and MMP-9 in meningioma cells compared to controls. A significant reduction in tumor invasion was determined with Matrigel gel and spheroid invasion assays in meningioma cells after transfection of these plasmids. Furthermore, downregulation of UPAR and MMP-9 reduced migration of tumor spheroids on vitronectin-coated plates. uPAR and MMP-9 downregulation suppressed capillary network formation, in both in vitro and in vivo models. Also,
\end{abstract}

Correspondence to: Dr J.S. Rao, Department of Cancer Biology and Pharmacology, University of Illinois College of Medicine at Peoria, One Illini Drive, Peoria, IL 61605, USA

E-mail: jsrao@uic.edu

Abbreviations: $\mathrm{uPA}(\mathrm{R})$, urokinase-type plasminogen activator (receptor); CMV, cytomegalovirus; PCR, polymerase chain reaction; PBS, phosphate-buffered saline; FITC, fluorescein-5isothiocyanate; DiI, 1'-dioctadecyl-3,3,3',3'-tetramethylindocarbocyanineperchlorate; $\mathrm{DiO}, 3,3^{\prime}$-dioctadecyloxacarbocyanine perchlorate; GFP, green fluorescent protein; ECM, extracellular matrix; EGFR, epidermal growth factor receptor; VEGF, vascular endothelial growth factor; HMEC, human endothelial cells

Key words: meningioma, tumor, invasion, angiogenesis it is well known that tumor cells manipulate intracellular signaling pathways to aid in various processes involved in tumor progression. Our study revealed that downregulation of UPAR and MMP-9 leads to a decrease in the activation of some of the important enzymes participating in the MAPK and PI3 kinase pathways, which in turn, might decrease cell survival and proliferation. In addition, we analyzed the efficiency of RNAi-mediated targeting of UPAR and MMP-9 in pre-established tumor growth in vivo. We observed a significant regression of pre-established orthotopic tumors upon RNAimediated targeting of uPAR and MMP-9. In addition, the present study indicated that targeting both the proteins simultaneously augmented the therapeutic treatment of human meningiomas.

\section{Introduction}

Meningiomas are the tumors that develop in the meninges, which are the membranes that surround brain and spinal cord. There are typically three layers of meninges: the outer dura mater, inner pia mater and middle arachnoid membrane made up of arachnoid cap cells. Meningiomas develop from the arachnoid cap cells and are usually attached to the dura mater. Among the tumors that develop in the central nervous system, meningiomas are the most commonly occurring tumors and account for $\sim 15-20 \%$ of all CNS tumors. Meningiomas can occur in any part of the brain or spinal cord, but $90 \%$ are intracranial tumors, cerebral hemispheres are the most common sites for the occurrence. Characteristic features of malignant meningiomas are high mitotic index, aggressive invasion into surrounding tissue, and occasional metastasis. In addition, rapid cell proliferation and the capacity of tumor cells to degrade histological barriers, basement membrane and interstitial stroma for invasion into adjacent tissue are hallmarks of malignancy.

Several researchers have demonstrated that a variety of proteolytic enzymes, such as serine proteases and metalloproteinases, play crucial roles in tumor invasion and metastasis in several types of cancers (1-6). The serine protease urokinase plasminogen activator (uPA) and its high affinity 
receptor, urokinase plasminogen activator receptor (uPAR), are responsible for extracellular degradation and cellular migration during various conditions such as inflammatory responses or tumor invasion (3). Furthermore, the uPA-uPAR system brings about several intracellular and intercellular processes including cleavage and activation of plasminogen to plasmin, remodeling of extracellular matrix (ECM), activation of growth factors, and initiation of intracellular signaling in response to various stimuli (7). As such, the uPAuPAR system plays a crucial role in cell adhesion, migration, invasion and cell proliferation, particularly in an altered environment such as cancer (8). Overexpression of UPAR has been reported in various cancers (9-11). Several earlier studies have revealed that UPAR is actively involved in initiating intracellular signaling events that contribute to tumor progression, invasion and metastasis (5,12-14). Downregulation of overexpressed UPAR in human carcinoma cells decreased phosphorylation of FAK and subsequently reduced activation of the ERK/MAPK pathway (15). Further, a number of earlier studies reported elevated levels of UPAR expression and related initiation of integrin-mediated intracellular signaling leading to activation of the MAPK/ ERK pathway and transcription factors that resulted in tumor progression (16). Finally, previous studies have demonstrated that uPA-uPAR signaling upregulates matrix metalloproteinase expression in various types of cancers $(1,2)$.

The matrix metalloproteinase (MMP) family is comprised of zinc-dependent endopeptidases that are crucial for various proteolytic events required for several aspects of tumor malignancy such as growth, angiogenesis and metastasis (17). Matrix metalloproteinases are also involved in ECM degradation, and therefore, contribute to tumor progression and metastasis. Matrix metalloproteinase-9 (MMP-9) has been reported to be actively involved in tumor growth, invasion, and angiogenesis in various types of cancers $(2,18-20)$. MMP-9 not only synchronizes with other matrix metalloproteinases and leads to degradation of extracellular matrix (21), but also plays a role in the release and processing of growth factors and growth factor receptors $(22,23)$. Elevated levels of MMP-9 and MMP-10 have been correlated with an anti-apoptotic effect on p53-mediated apoptosis in human colon adenocarcinoma cell lines (24). High expression of MMP-9 and VEGF as well as an associated rate of metastasis to the lymph node has been observed in gastric cancer (25). Our previous studies have shown that elevated levels of MMP-9 are correlated with histological grade of malignancy in gliomas (26). The downregulation of MMP-9 using antisense oligonucleotides (27) and RNAi interference of gene expression (28) have resulted in reduction of tumor invasion and angiogenesis.

All of the above findings support the pivotal roles played by UPAR and MMP-9 in malignancy conditions. Advances in the design and delivery of targeting molecules now allow efficient and highly specific gene silencing in mammalian systems. In recent years, RNA interference (RNAi) has emerged as a robust method of post-transcriptional silencing of genes using double-stranded RNA (dsRNA) with sequence complementary to a targeted gene. Small interfering RNA (siRNA) of about 21-23 nucleotides are generated intracellularly through dicer, a cellular ribonuclease III, which then mediates gene silencing by degradation/blocking of translation of the target mRNA (29). In the present study, our main interest was to analyze both in vitro and in vivo effects of downregulation of UPAR and MMP-9 in the malignant meningioma cell line IOMM-Lee using RNAi constructs for these molecules. Our study revealed that RNAi targeting resulted in the downregulation of UPAR and MMP-9 gene expression, invasion, migration, angiogenesis and tumor growth in both in vitro and in vivo models. Taken together, the results of the present study suggest that RNAi-mediated gene silencing of UPAR and MMP-9 may prove to be an effective therapeutic application in the treatment of malignant meningiomas.

\section{Materials and methods}

Construction of plasmid vectors for expression of siRNA directed against $U P A R$ and MMP-9. A pcDNA3 plasmid was used for construction of vectors expressing short hairpin RNA (shRNA) for uPAR (pUR), MMP-9 (pM), and uPAR and MMP-9 simultaneously (pUM) and scrambled vector (pSV) as described previously by our group (30).

Cell culture conditions and transfection. In the present study, we used the established human meningioma cell line IOMMLee (kindly provided by Dr Ian McCutcheon, U.T. M.D. Anderson Cancer Center, Houston, TX). This cell line was successfully established from recurrent primary intraosseous malignant meningioma of the skull. The cells were maintained in Dulbecco's modified Eagle's medium (Mediatech, Herndon, VA) supplemented with $10 \%$ fetal bovine serum, $100 \mu \mathrm{g} / \mathrm{ml}$ streptomycin and $100 \mathrm{U} / \mathrm{ml}$ penicillin (Invitrogen, Carlsbad, $\mathrm{CA}$ ) at $37^{\circ} \mathrm{C}$ in a humidified atmosphere containing $5 \% \mathrm{CO}_{2}$. IOMM-Lee cells were transfected with pSV, pUR, pM and pUM using lipofectamine reagent (Invitrogen, Grand Island, NY) per manufacturer's instructions. Transfected cells were maintained in serum-containing media for $48 \mathrm{~h}$ before further use in various procedures. For immunostaining, the transfection of cells was carried out in Lab-Tek II chamber slides (Nalge Nunc International, Naperville, IL).

Reverse transcription-PCR analysis of downregulation of mRNA for UPAR and MMP-9 following transfection with $p S V, p U R, p M$ and $p U M$. Total RNA was extracted from untreated parental cells and also from IOMM-Lee cells after a 48-h incubation period following transfection with pUR, $\mathrm{pM}, \mathrm{pUM}$ and $\mathrm{pSV}$. RNA was DNase-treated and reverse transcription reaction was set up using $\mathrm{RT}$ reaction mix (Invitrogen, Carlsbad, CA). The resultant cDNA was then used for PCR with primers for UPAR, MMP-9, and GAPDH and products were analyzed on $1 \%$ agarose gel electrophoresis.

Western blot analysis. Cellular protein extracts were obtained using a lysis buffer (Tris-buffered saline, $20 \mathrm{mM}$ EDTA, 0.1\% Triton X-100) $48 \mathrm{~h}$ after transfection with pSV, pUR, pM and pUM. Cell lysates were also collected from untreated parental cells to serve as the control (mock). Protein concentration was determined using a bicinchoninic acid procedure (Pierce, Rockford, IL). Equal amounts of protein were then subjected to SDS-PAGE using gels with appropriate percentage of acrylamide (suitable to molecular weight of protein probed) 
followed by transfer of protein to polyvinylidene difluoride membranes (Bio-Rad, Hercules, CA). Membranes were then blocked in 5\% non-fat dry milk in phosphate-buffered saline (PBS), incubated with primary antibodies in blocking solution (1:1000 dilution) for either $2 \mathrm{~h}$ or overnight at $4^{\circ} \mathrm{C}$ as required. Membranes were then washed twice with T-PBS [Tween-20 $(0.1 \%)$, phosphate-buffered solution] at 15 -min intervals. Appropriate horseradish peroxidase-conjugated secondary antibodies (Biomeda, Burlingame, CA) were used at a 1:2000 concentration and the membranes were developed following an enhanced chemiluminescence protocol (Amersham Biosciences, Piscataway, NJ). The membranes were further probed for GAPDH, which served as loading control. The immunoblots were then scanned to analyze for protein expression of various treatments.

Gelatin zymography. PMA-induced MMP-9 expression was analyzed using zymography after transfection of IOMM-Lee cells with pSV, pUR, pM and pUM. Serum-containing media was replaced with serum-free media and the cells were stimulated with $100 \mathrm{nM}$ PMA $24 \mathrm{~h}$ after transfection. Conditioned media was collected from cells after a further 24-h incubation period and centrifuged to remove cellular debris. Conditioned media was also collected from untreated cells maintained under similar conditions and analyzed as the control (mock). Equal amounts of protein $(30 \mu \mathrm{g})$ were subjected to electrophoresis on $10 \%$ SDS polyacrylamide gels containing gelatin $(0.5 \mathrm{mg} / \mathrm{ml})$. Gels were stained with amido black (Sigma-Aldrich, St. Louis, MO) and gelatinase activity of MMP-9 was visualized as clear bands on a dark blue background at areas corresponding to the molecular weight of MMP-9 protein.

Immunofluorescence analysis of in situ protein expression. IOMM-Lee cells were cultured in 8-well chamber slides at a concentration of $5 \times 10^{3}$ cells/well. After a 24 -h incubation period, cells were transfected with pSV, pUR, pM and pUM. Untreated cells were also cultured in similar conditions to serve as the control. Following incubation for $48 \mathrm{~h}$, cells were fixed with $3.7 \%$ formaldehyde and then blocked with $1 \%$ bovine serum albumin (BSA) for $1 \mathrm{~h}$ at room temperature. The slides were then incubated with primary antibodies diluted to a concentration of $1: 200$ in BSA overnight at $4^{\circ} \mathrm{C}$. Slides were washed three times with PBS to remove excess primary antibody, and cells were then incubated in anti-mouse Texas Red or anti-rabbit FITC conjugated IgG (suitable to primary antibody) at a concentration 1:500 for $1 \mathrm{~h}$ at room temperature. The slides were washed three times with PBS, mounted with 4', 6-diamidino-2-phenylindole (DAPI) to visualize nucleus, covered with glass cover slips and fluorescence photomicrographs were obtained.

Cell proliferation assay. Cell Titer $96^{\mathrm{TM}}$ colorimetric assay was used to determine viable cell mass in both untreated IOMM-Lee cells and cells transfected with pSV, pUR, pM and pUM. IOMM-Lee cells were cultured in triplicate in 96-well plates at a concentration of $5 \times 10^{3}$ and transfected with $1 \mu \mathrm{g}$ of the siRNA plasmid vectors per standard protocol. Untreated cells were maintained under similar conditions to serve as the control (mock). Forty-eight hours after transfection, the cells were maintained for different time intervals in serum-supplemented media for 1-5 days. At each time-point, $10 \mu 1$ of freshly prepared MTT [3-(4,5-dimethylthiazol-2yl)2,5-diphenyltetrazolium; Sigma-Aldrich] reagent $(5 \mathrm{mg} / \mathrm{ml}$ sterile PBS) was added to each well and the cells were further incubated for $4 \mathrm{~h}$. The cells were treated with detergent $(2 \mathrm{ml}$ isopropanol supplemented with $6.66 \mu \mathrm{l}$ concentrated $\mathrm{HCl}$ ) and mixed thoroughly for color development. A570 was measured using an ELISA plate reader. The OD values obtained were plotted against the respective time intervals. The reduction in cell proliferation following knockdown of uPAR and MMP-9 was quantified as the decrease in the intensity of MTTFormazan (blue color measured calorimetrically at $570 \mathrm{~nm}$ ) at different time intervals in the IOMM-Lee cells treated with plasmid vectors compared to the untreated cells (mock).

Spheroid migration assay. IOMM-Lee cells $\left(7 \times 10^{4}\right)$ labeled with GFP (green fluorescence protein) were cultured in $0.5 \%$ agarose-coated 96-well plates and grown for 3 to 4 days at $37^{\circ} \mathrm{C}$, with shaking at 40-60 rpm with occasional replacement of media. The spheroids were transfected with $\mathrm{pSV}, \mathrm{pUR}$, pM and pUM. Untreated spheroids were maintained in similar conditions to serve as the control (mock). Forty-eight hours after transfection, the spheroids were transferred to vitronectin (50 $\mathrm{mg} / \mathrm{ml}$ )-coated 8-well chamber slides and maintained in serum-free media for $72 \mathrm{~h}$. Migration of the cells from spheroids was measured using fluorescenc microscopy $72 \mathrm{~h}$ later. The migration of the spheroids was quantified as the distance cells migrated from the spheroids and plotted against the respective plasmid vectors used for treatment of spheroids.

Matrigel invasion assay. IOMM-Lee cells $\left(1 \times 10^{6}\right)$ were transfected with pSV, pUR, pM and pUM. Cells were incubated for $48 \mathrm{~h}$, trypsinized, counted and $1 \times 10^{5}$ cells were cultured in the upper chamber of a Transwell insert ( $8-\mu \mathrm{M}$ pores) coated with Matrigel (1 mg/ml) (Collaborative Research Inc., Waltham, MA). The cells were supplemented with $500 \mu 1$ serum-free media. The lower chamber was filled with $700 \mu 1$ DMEM media supplemented with serum that served as a chemoattractant for the migrating cells. The plates were maintained in an incubator at $37^{\circ} \mathrm{C}$. Untreated cells were also maintained under similar conditions to serve as the control (mock). Forty-eight hours after incubation, the chambers were removed from the incubator, non-migrated cells in the upper chamber were scraped off carefully, and migrated cells adhering to the lower surface of the Transwell insert were stained with Hema-3. Photographs of the cells were taken at magnification $\mathrm{x} 20$ with a light microscope. The cells were counted and quantification of invasion was performed as described previously (31).

Spheroid invasion assay. IOMM-Lee cells (7x104) were cultured in $0.5 \%$ agarose-coated 96 -well plates. The cells were grown in $80 \mu \mathrm{l}$ serum supplemented DMEM media for 3-4 days, with shaking at 40-60 rpm and periodic replacement of media. Spheroids with 100-200 $\mu \mathrm{M}$ diameters were selected for the present study. The spheroids were transfected with $\mathrm{pSV}, \mathrm{pUR}, \mathrm{pM}$ and pUM and labeled with the lipid red fluorescence dye Dil (1,1'-dioctadecyl-3, 3, 3', 3'-tetra methyl indocarbocyanine perchlorate; Molecular Probes; Invitrogen, 
Carlsbad, CA). Simultaneously, untreated spheroids were also maintained to serve as the control (mock). Fetal rat brain cells (16-17 days old) were cultured in 6-well plates and grown for 21 days at $37^{\circ} \mathrm{C}$ with shaking at $40-60 \mathrm{rpm}$. The fetal rat brain cell aggregates were then labeled with the lipid green fluorescence dye $\mathrm{DiO}$ (3, 3'-dioctadecyloxacarbocyanine perchlorate; Molecular Probes; Invitrogen, Carlsbad, CA). Both the fluorescent dyes used in the present study are reported as non-toxic to cells, and thus, do not effect the invasive ability of the tumor cells. Forty-eight hours after transfection, the tumor spheroids (treated and control) and fetal rat brain cell aggregates were co-cultured in 96-well low attachment plates and maintained for another $72 \mathrm{~h}$ in serum-free media. The gradual invasion of tumor spheroids into fetal rat brain cell aggregates was recorded using confocal microscopy at 24,48 and $72 \mathrm{~h}$. The percentage of invasion was then quantified using image analysis software as the area of fetal rat brain aggregates (FRBA) remaining uninvaded by the tumor spheroids. The values were plotted against the respective time intervals.

In vitro angiogenesis assay. IOMM-Lee cells $\left(4 \times 10^{4}\right)$ were cultured in 8-well culture slides. After $24 \mathrm{~h}$, the cells were transfected with pSV, pM, pUR and pUM and allowed to grow for another $24 \mathrm{~h}$. Untreated cells were maintained to serve as the control (mock). Twenty-four hours after transfection, serum-containing media was replaced with serum-free DMEM media. After 48 h, conditioned media was collected from transfected cells and untreated cells. Simultaneously, $3 \times 10^{4}$ HMEC cells were grown for $24 \mathrm{~h}$ in 8 -well chamber slides. After $24 \mathrm{~h}$, serum-containing media was removed from HMEC cultures and replaced with conditioned media collected from untreated cells and cells transfected with the shRNA plasmids. The cells were further grown in conditioned media for $72 \mathrm{~h}$ followed by H\&E staining. Pictures were taken using a light microscope and observed for capillary-like network formation. The percentage of network formation was quantified as the product of the number of branch points formed by endothelial cells multiplied by the branches from each point and plotted against respective treatments.

In vivo angiogenesis assay (dorsal skin-fold chamber model). Previously established protocol (32) was used to detect in vivo angiogenesis in the presence of IOMM-Lee parental cells (mock) and cells treated with pSV, pUR, pM and pUM. Diffusion chambers (Fisher Scientific, Pittsburgh, PA) were prepared by aligning $0.45 \mu \mathrm{M}$ Millipore membranes (Fisher Scientific) on both sides of the rim of the 'O' ring (Fisher Scientific) with sealant prepared from a mixture of $250 \mathrm{mg}$ dental acrylic, $3 \mathrm{ml}$ dichloroethane, and $200 \mu 1$ 2-butanone. Chambers were dried and sterilized with ultraviolet light for 30 min. IOMM-Lee cells $\left(2 \times 10^{6}\right)$, suspended in sterile PBS, were then injected into the chambers through the opening provided in the chambers. The chambers were then sealed with bone wax and placed in serum-free media to keep them wet until use. Animals were anesthetized as mentioned above, and a dorsal air sac was created by injecting $5 \mathrm{ml}$ air. A 1.52 -cm incision was made along the edge of the dorsal air sac. The chambers were carefully placed through the incision under the skin, and the incision was closed using sealing animal glue.
Ten days later, the animals were sacrificed. The skin around the implanted chambers was carefully removed and observed under a light microscope. Novel branches (irregularly arising branches from the regular organized blood vessels) were recorded as tumor-induced neovasculature.

Treatment of orthotopic intracranial tumors. In vivo effect of the downregulation of the serine protease uPA receptor and the matrix metalloproteinase MMP-9 was assessed by intracranial injection of IOMM-Lee cells into nude mice followed by treatment of the brain tumors with intracranial osmotic pumps. IOMM-Lee cells were cultured in serumcontaining DMEM media and trypsinized. The cells were then washed twice with serum-free DMEM media and counted with a hemocytometer. Cells $\left(0.5 \times 10^{6}\right)$, suspended in $10 \mu \mathrm{l}$ sterile PBS, were injected into anesthetized nude mice $(50 \mathrm{mg} / \mathrm{kg}$ ketamine, $10 \mathrm{mg} / \mathrm{kg}$ xylazine) using a stereotactic frame as previously described (33). Tumors were allowed to grow for one week and the animals were divided into 5 groups with six animals in each group. Alzet mini osmotic pumps (Durect Corporation, CA) containing $150 \mu \mathrm{g}$ of $\mathrm{pSV}, \mathrm{pUR}, \mathrm{pM}$ and pUM $(100 \mu 1$ of plasmid with $1.5 \mu \mathrm{g} / \mu \mathrm{l})$ were used. The animals were observed for $\sim 3-4$ weeks. Once control animals showed chronic symptoms, the animals were euthanized by cardiac perfusion first using PBS followed by $10 \%$ formalin. The brains were removed and stored in $10 \%$ formalin and embedded in paraffin as per standard protocol. Sections were prepared and stained with H\&E. The tumor sections were scored semi-quantitatively; the average cross-sectional diameter was used to calculate tumor size and compared between the control and treated groups.

Immunohistochemical analysis of protein expression in tumor sections. Paraffin-embedded tumor sections were subjected to rehydration by passing through a series of xylene and $100 \%$ and $90 \%$ ethanol. Endogenous peroxidase activity was blocked by treating the cells with $0.01 \% \mathrm{H}_{2} \mathrm{O}_{2}$ in methanol. The slides were washed in cold PBS and blocked for $30 \mathrm{~min}$ in $1 \%$ BSA prepared in PBS (prevents non-specific binding) followed by overnight incubation in primary antibody for UPAR and MMP-9 at a concentration of $1: 100$ at $4^{\circ} \mathrm{C}$. The slides were then washed three times with $1 \%$ BSA in PBS at 2-min intervals and incubated in secondary antibody for $1 \mathrm{~h}$. Following incubation with the secondary antibody, the slides were washed three times with cold PBS and further incubated in DAB (3, 3' Di amino benzidine; Sigma-Aldrich). DAB interacts with the reporter enzyme (horseradish peroxidase) conjugated to secondary antibody to give brown staining at regions of protein expression. The slides were further washed with sterile water and subjected to dehydration. After dehydration, the slides were stained with hematoxylin to visualize nucleus, mounted and observed under a light microscope. Fields with brown stain resulting from DAB interaction were scored for protein expression.

\section{Results}

RNA interference inactivated expression of UPAR and MMP-9 in IOMM-Lee cells. Semi-quantitative RT-PCR analysis of DNA from the transfected cells from pUR, pM, and pUM 


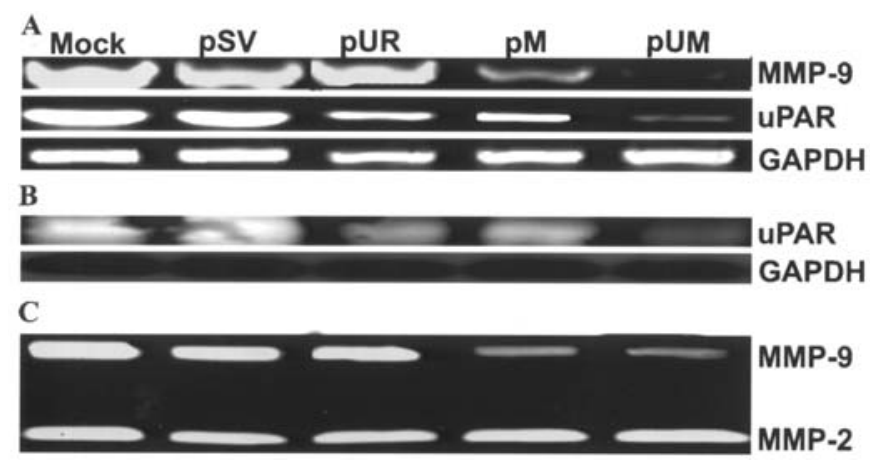

Figure 1. RNAi-mediated knockdown of UPAR and MMP-9 expression in IOMM-Lee cells. (A) Semi-quantitative RT-PCR of RNA extracted from IOMM-Lee parental cells (mock) and cells transfected with shRNA plasmids pSV, pUR, pM and pUM. RT-PCR reaction was also performed for GAPDH and served as a loading control. (B) Following transfection with cell lysates from pSV, pUR, pM and pUM, cells and parental cells (mock) were probed for UPAR using a specific antibody for UPAR by Western blot analysis. GAPDH was analyzed as a loading control. (C) Enzymatic activity of MMP-9 was analyzed in the conditioned media collected from cells transfected with pSV, pUR, pM, pUM and parental cells. Thirty $\mu \mathrm{g}$ of protein was loaded onto $10 \%$ SDS-PAGE containing gelatin.

revealed a significant decrease in mRNA levels of UPAR and MMP-9 as compared to cells transfected with mock or scrambled vector (Fig. 1A). The reduction in mRNA level was more significant with pUM transfection as compared to transfection with either of the single constructs. The uPAR protein levels were significantly decreased with pUR and pUM transfected cells compared to controls, pSV- and pM- transfected cells (Fig. 1B). Enzymatic activity of MMP-9 was analyzed in conditioned media collected from mock cells as well as from cells treated with pSV, pUR, pM and pUM using gelatin zymography (Fig. 1C). MMP-9 activity decreased significantly in the conditioned media collected from pM- and pUM-treated cells when compared to mock, pSV- and pUR-treated cells. Cells treated with pUM exhibited lower MMP-9 activity than cells treated with pM. However, no change was observed in MMP-2 activity. GAPDH levels were analyzed at the mRNA and protein levels to serve as a loading control and no differences were observed. The scrambled vector also did not have any effect on the mRNA and protein levels. Immunofluroscence detection for in situ expression of UPAR and MMP-9 using specific antibodies for these molecules revealed significant reduction of these molecules after transfection with single and bicistronic constructs for UPAR and MMP-9 compared to controls and pSV-treated cells (Fig. 2).

RNAi-mediated abrogation of $U P A R$ and MMP-9 gene expression reduced IOMM-Lee cell proliferation. Earlier studies have reported that cultured cancer cells overexpress uPAR, which in turn accelerates cell proliferation through interaction with integrins and growth factor receptor kinases such as EGF and PDGF (34). Overexpression of MMP-9 was also observed in cancer conditions where there is excessive cell proliferation (35). In the present study, we analyzed the proliferation efficiency of IOMM-Lee cells upon downregulation of uPAR and MMP-9. RNAi-mediated knockdown of UPAR and MMP-9 decreased proliferation efficiency of

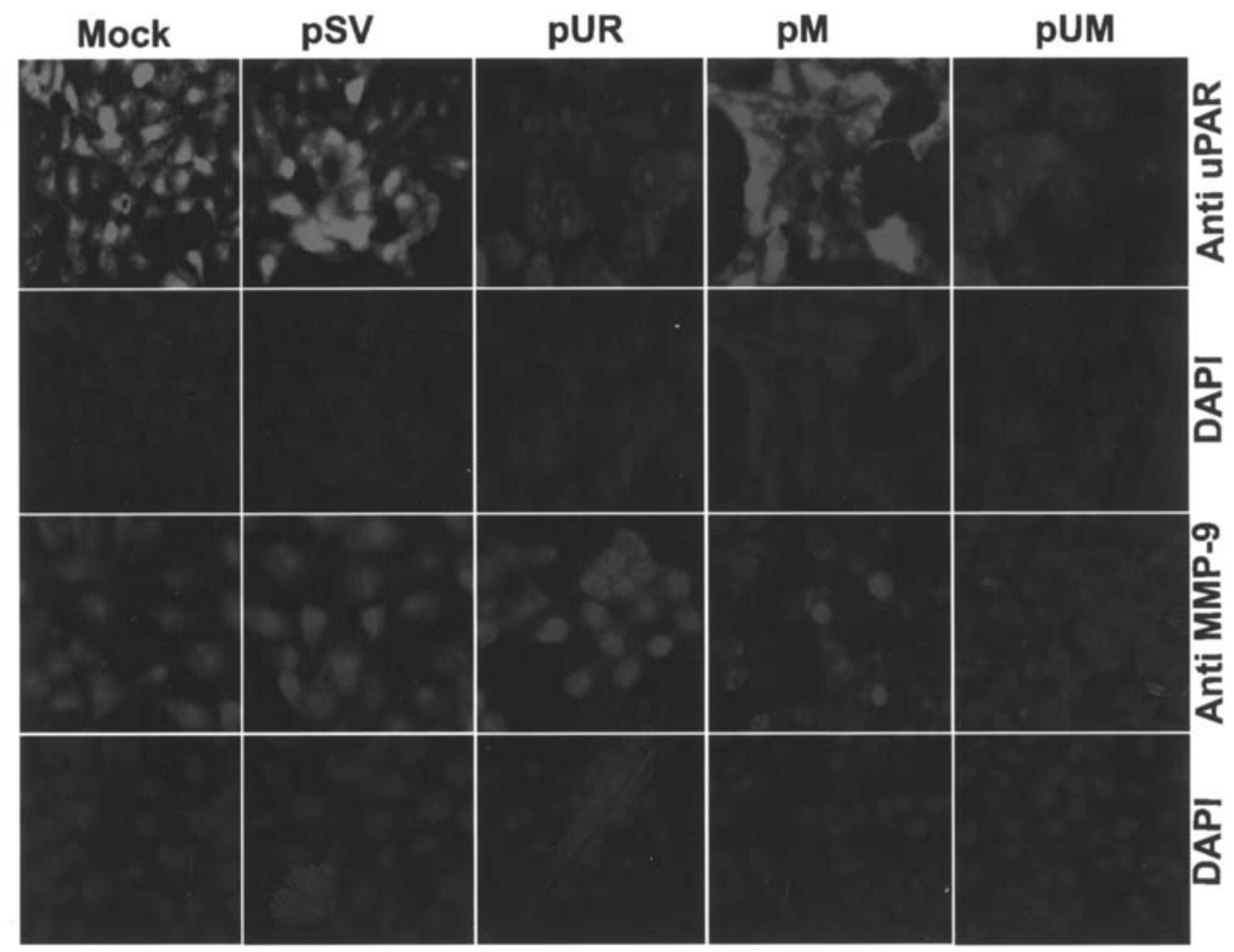

Figure 2. Immunofluorescence detection for in situ expression of uPAR and MMP-9. IOMM-Lee cells (5x104) were cultured in 8-well chamber slides and transfected with pSV, pUR, pM, and pUM. Parental cells (mock) were simultaneously maintained. Seventy-two hours following transfection, the cells were fixed in formaldehyde and processed to detect expression of uPAR and MMP-9. The cells were mounted with 4', 6-diamidino-2-phenylindole (DAPI) to visualize the nucleus. 


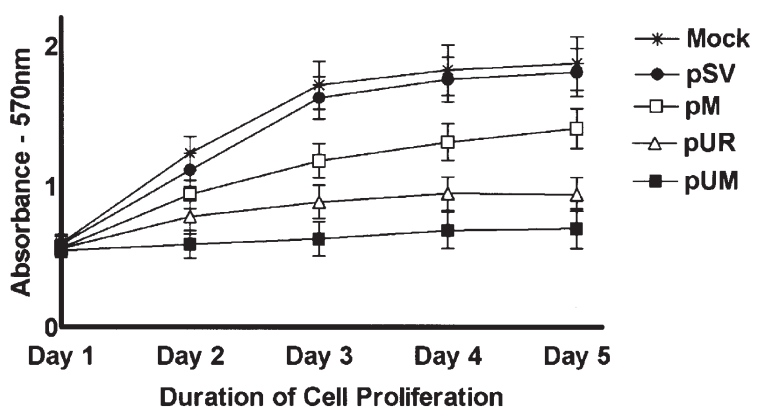

Figure 3. IOMM-Lee cell proliferation decreases following RNAi-mediated reduction of UPAR and MMP-9 gene expression. IOMM-Lee cells were maintained in triplicate in 96-well plates at a concentration of $5 \times 10^{3}$ and transfected with pSV, pUR, pM and pUM as described in Materials and methods. Forty-eight hours after transfection, viable cell mass was measured in both parental and treated cells at different time intervals (1-5 days). $\mathrm{A}_{570}$ was plotted against the respective time intervals. Mean \pm SD values from 3 different experiments are shown $(\mathrm{p}<0.001)$.

cells when compared to parental and pSV-transfected cells. Furthermore, a significant decrease in cell proliferation was observed in the IOMM-Lee cells transfected with pUM when compared to cells transfected with either pUR or pM (Fig. 3).

Knockdown of $U P A R$ and MMP-9 resulted in regression of tumor cell migration and invasion. Proteolytic enzyme cascades operating at the cell surface and in the extracellular environment play important roles in cellular migration, an essential process for tumor invasion and metastasis. Several earlier studies have established the role of the UPA-uPAR enzyme system and matrix metalloproteinases such as MMP-9 in migration and invasion of tumor cells into surrounding tissue. To determine whether uPAR and MMP-9 siRNA expression is capable of influencing tumor cell migration, we transfected IOMM-Lee cell spheroids with pSV, pUR, pM, and pUM vector. As shown in Fig. 4A, there was much higher cell migration from spheroids transfected with $\mathrm{pSV}$ and up to $50 \%$ inhibition of migration was observed with single construct transfected spheroids. However, cell migration from tumor spheroids was completely inhibited in spheroids transfected with the pUM vector. The migration of control and SV-transfected spheroids was significantly higher $(\mathrm{p}<0.001)$ compared to pUR-, pM- and pUM-transfected spheroids as quantitated by the number of cells migrating out from the spheroids (Fig. 4B). Based on the observation that siRNAmediated downregulation of UPAR and MMP-9 decreased migration of the IOMM-Lee cells from spheroids, we next investigated the effect of the downregulation of these enzymes on invasion following transfection with the shRNA plasmid vectors for these molecules. Downregulation of UPAR and MMP-9 showed a reduction in the number of cells that invaded through the Matrigel when compared to parental and pSVtransfected cells. Furthermore, we observed a more significant decrease in the invasion of pUM-treated IOMM-Lee cells when compared to the cells treated with either of the single constructs (Fig. 4C and D). The effect of RNAi for these molecules was further evaluated in a three-dimensional spheroid invasion model. Spheroids derived from IOMM-Lee cells were transfected with pSV, pUR, pM and pUM and co-cultured with fetal rat brain aggregates. The parental cell and pSV-transfected spheroids attached efficiently and invaded fetal rat brain aggregates, whereas those transfected with pUR, pM and pUM showed poor attachment and invasion. Moreover, spheroids transfected with the bicistronic construct, pUM, showed more significantly poorer attachment and invasion of brain aggregates when compared to the single constructs, pUR and pM (Fig. 4E and F).

Inhibition of tumor cell-induced capillary network formation by $p U M$ vector. The growth of meningeal tumors depends on the induction of new capillary blood vessels, which is necessary to support the developing tumor mass. In this study, we used a co-culture system in which microvascular endothelial cells were induced by meningeal cells to form capillary-like structures in order to examine the RNAi-mediated suppression of UPAR and MMP-9. Mock and pSV-transfected cells showed well-defined capillary network formation within $72 \mathrm{~h}$. In contrast, transfection of IOMM-Lee cells with the vector expressing siRNA for UPAR and MMP-9 completely inhibited tumor cell-induced microvessel morphogenesis (Fig. 5A). The quantification of branch points and number of branches were undetectable in pUM-transfected co-cultures compared to controls and pSV (Fig. 5B). Furthermore, the effect was only $45-55 \%$ in pUR- and pM-treated co-cultures compared to controls and the pSV-treated group (Fig. 5B).

The dorsal skin fold chamber model was used to assess in vivo angiogenesis to confirm the in vitro co-culture experiments. Diffusion chambers containing $2 \times 10^{6}$ IOMM-Lee cells (parental cells or cells transfected with pSV, pUR, $\mathrm{pM}$ and $\mathrm{pUM}$ ) were introduced into athymic nude mice as described earlier. Mice receiving either parental or pSVtreated IOMM-Lee cells showed a dense network of fine, curly microvessels arranged in an irregular pattern when compared to properly organized pre-existing vasculature. However, IOMM-Lee cells transfected with pUR and pM induced microvessel formation to a lesser extent as compared to either parental or pSV-transfected cells. Finally, IOMM-Lee cells transfected with pUM showed almost zero microvessel formation (Fig. 5C).

UPAR and MMP-9 downregulation through RNAi treatment interfered with intracellular signaling events. Chemical signals generated at the cell surface are transferred to the intracellular environment through several signaling cascades and induce intracellular events. The signaling cascades include growth factors, transmembrane receptor proteins and messenger proteins that actively undergo phosphorylation and thus transfer the signal. The signal transduction pathways are reported to undergo major modification during tumor growth. Since earlier reports confirmed that the MAPK and PI3 kinase pathways are actively involved in signal transduction during tumor progression (36), we evaluated the expression and phosphorylation of proteins involved in these pathways through Western blotting. Fig. 6 shows that RNAi treatment had no effect on the expression of total ERK I (p42), ERK II (p44), JNK and P38, whereas there was a significant decrease in phosphorylation of ERK I, ERK II and P38 in the cells treated with pUR, pM and pUM as compared to parental and pSVtransfected cells. Furthermore, the decrease was significant in 

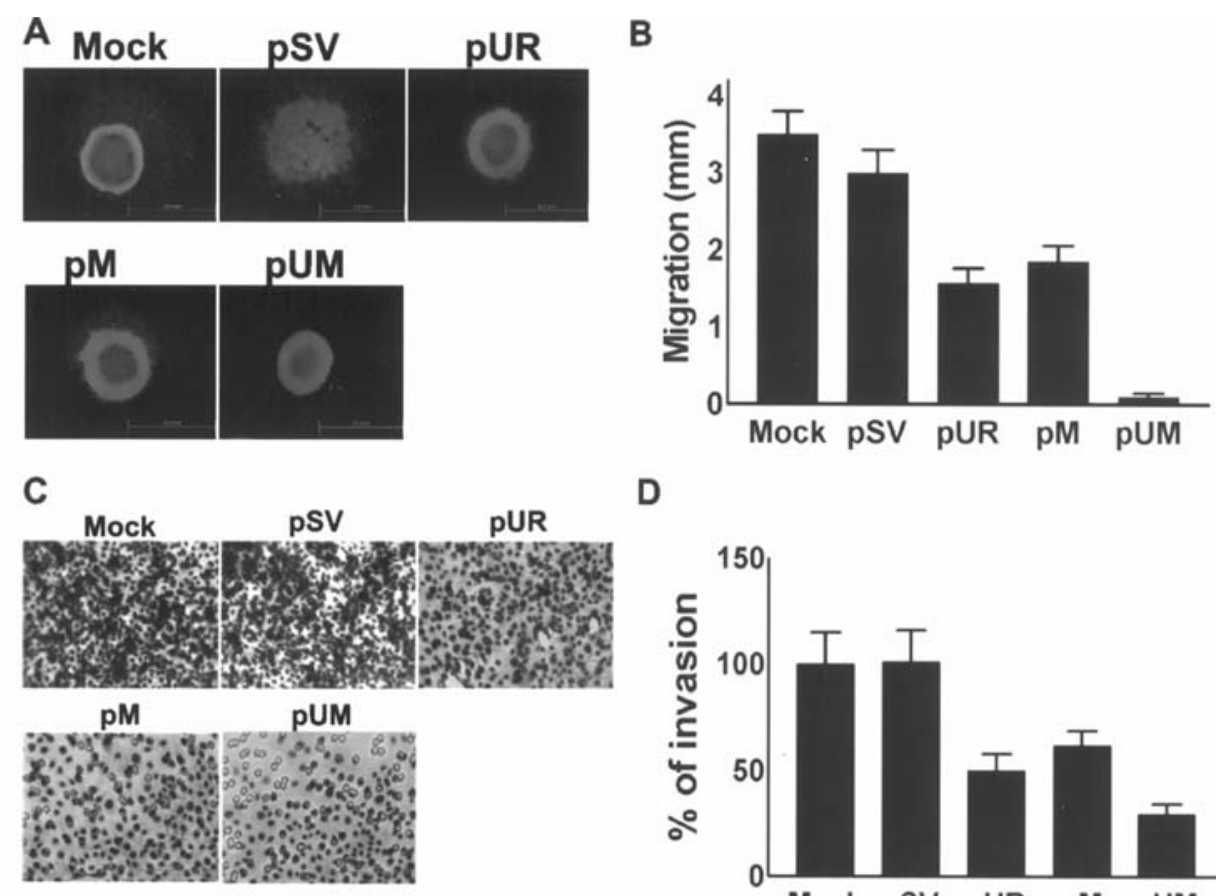

D

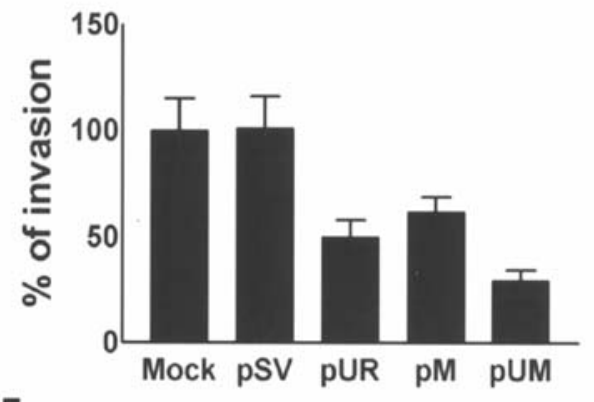

E

$\mathbf{F}$
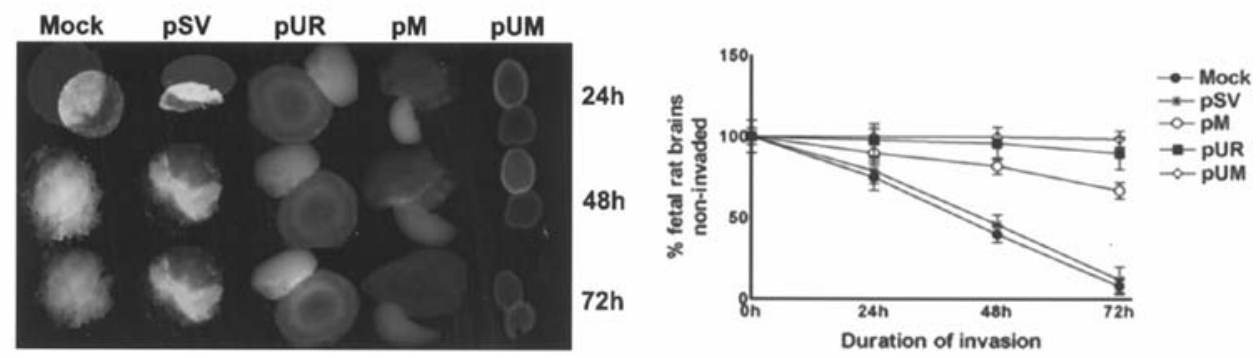

Figure 4. Downregulation of uPAR and MMP-9 expression through RNAi treatment abated spheroid migration on vitronectin-coated substrate. (A) IOMMLee-GFP cells $\left(7 \times 10^{4}\right)$ were cultured in 96-well low attachment plates and spheroids were allowed to grow for 3-4 days with shaking at $40-60 \mathrm{rpm}$ at $37^{\circ} \mathrm{C}$. The spheroids were then transfected with shRNA plasmids pSV, pUR, pM and pUM. Untreated spheroids were also maintained to serve as the control (mock). Forty-eight hours after transfection, the spheroids were transferred to vitronectin-coated $(50 \mathrm{mg} / \mathrm{ml}) 8$-well chamber slides and maintained for another $72 \mathrm{~h}$ in serum-free media. Migration of spheroids was analyzed after taking pictures under a fluorescent microscope. (B) Migration was quantified as the distance spheroid cells moved away from spheroids on vitronectin-coated substrate. Values are mean \pm SD from three different experiments $(\mathrm{p}<0.001)$. $(\mathrm{C})$ IOMM-Lee cells were transfected with pSV, pUR, pM and pUM. Untransfected cells (mock) were also maintained to serve as a control. Forty-eight hours later, the cells were trypsinized, counted and $1 \times 10^{5}$ cells were cultured in the upper chamber of a Transwell insert coated with Matrigel (1 mg/ml) and processed per manufacturer's instructions. (D) Number of cells was counted in three different fields for each sample and the percentage invasion of cells treated with shRNA plasmids was analyzed in comparison with the untreated (mock) cells. The graph represents the percentage invasion shown by the cells transfected with pSV, pUR, pM and pUM in comparison with untreated cells (mock). Values are mean \pm SD from three different experiments $(\mathrm{p}<0.001)$. (E) IOMM-Lee cells $\left(7 \times 10^{4}\right)$ were cultured in 96-well low attachment plates and allowed to grow for 3-4 days with shaking at $40-60 \mathrm{rpm}$ at $37^{\circ} \mathrm{C}$. The spheroids were later transfected with pSV, pUR, pM and pUM. Forty-eight hours after transfection, the cells were labeled with Dil (red fluorescent dye). Untreated spheroids (mock) were maintained as control under similar conditions. Simultaneously fetal rat brain aggregates (FRBA) were grown from 16- to 17-day-old fetal rat brain cells and labeled with DiO (green fluorescent dye). Later, both the IOMM-Lee spheroids and spheroids from fetal rat brain cells were cocultured and maintained in serum-free media. Invasion of fetal rat brain spheroids by tumor cell spheroids was recorded at 24,48 and $72 \mathrm{~h}$ using a fluorescent microscope and quantified. (F) The percentage invasion of the untransfected spheroids and spheroids treated with shRNA plasmids was quantified using image analysis software and plotted as the fetal rat brain aggregates remaining uninvaded against different time intervals. Values shown are the mean \pm SD from three different experiments $(\mathrm{p}<0.001)$

pUM-transfected cells when compared to either parental and pSV-transfected cells or cells transfected with pUR and pM (single constructs). FAK protein analysis revealed that the expression of total FAK was not affected by RNAi treatment of IOMM-Lee cells but phosphorylation of FAK decreased significantly in pUR-, pM- and pUM-treated cells when compared to mock and pSV-treated cells. GAPDH was analyzed as a loading control and confirmed that equal amounts of protein were loaded and that the downregulation effect was due to the RNAi treatment.
We observed a similar trend of downregulation during analysis of key proteins that participate in the PI3 kinase pathway (Fig. 6). Expression of PI3 kinase was slightly decreased in the cells transfected with pUR, pM and pUM when compared to parental and pSV-transfected cells. We detected a significant decrease in the phosphorylation of Akt and mTOR in the pUR-, pM- and pUM-treated cells when compared to parental and pSV-transfected IOMM-Lee cells. Among the plasmid vectors targeting UPAR and MMP-9, the decrease was most significant in pUM-treated cells. Taken 


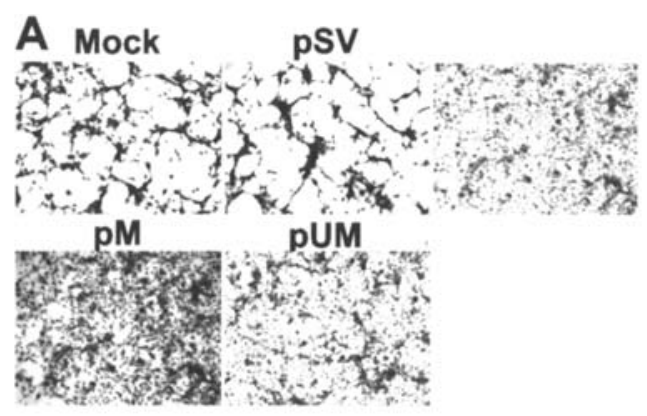

C

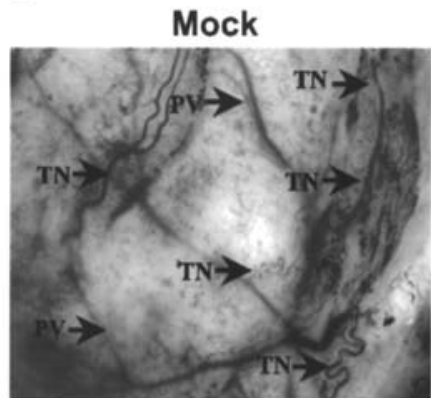

pM

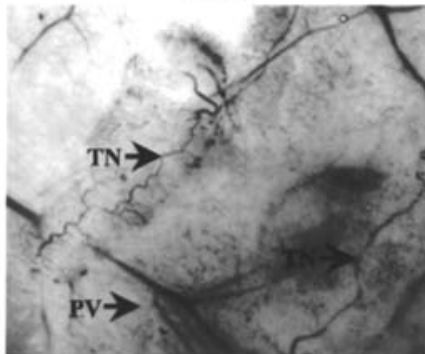

B

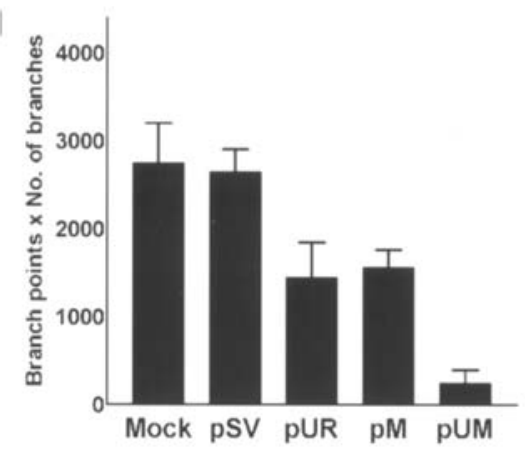

Figure 5. Targeting uPAR and MMP-9 through RNAi treatment reduced angiogenesis initiated by IOMM-Lee cells. (A) IOMM-Lee cells (4x104) were cultured in 8-well chamber slides and transfected with pSV,pUR, pM and pUM and grown for 24 h. At the same time, untreated cells (mock) were maintained for the control. After $24 \mathrm{~h}$, the media was replaced with serum-free media and maintained for another $24 \mathrm{~h}$. Simultaneously, HMEC cells ( $\left.3 \times 10^{4}\right)$ were maintained in 8-well chamber slides. Twenty-four hours following addition of serum-free media to transfected IOMM-Lee cells, the conditioned media was collected and added to the HMEC cells. The HMEC cells were grown in conditioned media for another $72 \mathrm{~h}$, stained with H\&E and capillary network formation was analyzed with light microscopy. (B) The ability of capillary network formation was analyzed as number of branch points and number of branches per branch point and plotted against the respective cells. Values represent mean \pm SD from three different experiments. (C) Dorsal skin fold chamber model revealed inhibition of in vivo angiogenesis as a result of RNAi-mediated abrogation of uPAR and MMP-9. Diffusion chambers holding 2x10 ${ }^{6}$ IOMMLee parental cells and cells transfected with pSV,pUR, pM and pUM were introduced into dorsal air sacs of athymic nude mice as described in Materials and methods. Ten days after introduction of the diffusion chambers, the animals were sacrificed. The skin around the chamber was carefully removed and observed under light microscope. Delicate zigzag-shaped microvessels showing irregular arrangement when compared to more organized pre-existing vasculature (PV) were recorded as tumor-induced neovasculature (TN).
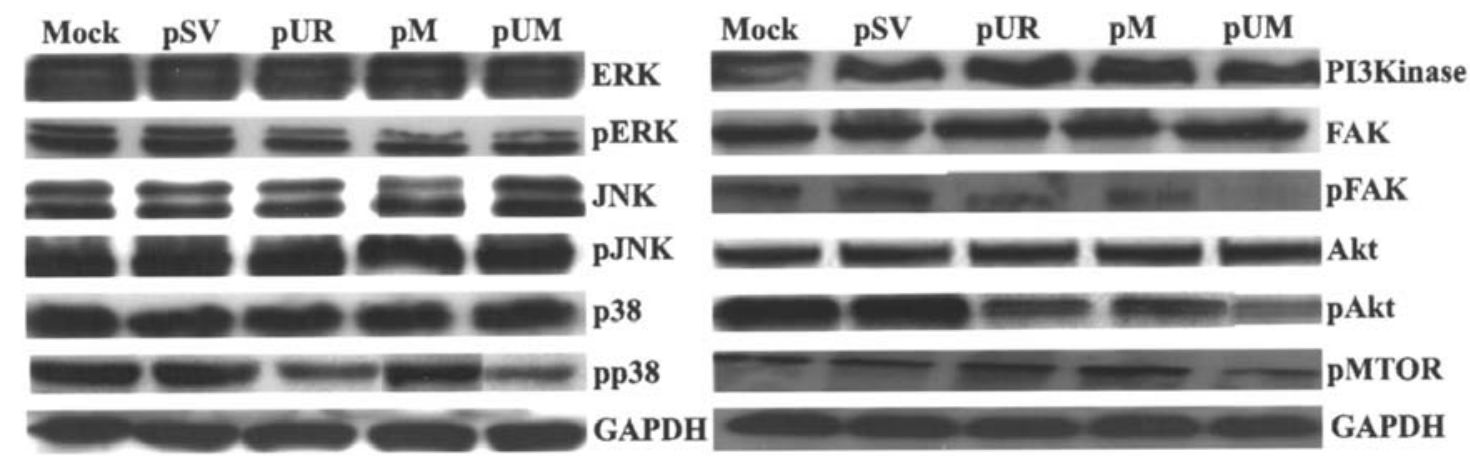

Figure 6. RNAi-mediated downregulation of uPAR and MMP-9 modulates downstream signaling events. IOMM-Lee cells were transfected with pSV, pUR, pM and pUM. Simultaneously, untreated cells (mock) were maintained to serve as the control. The cells were lysed after 48 h and the cell lysates were analyzed for various proteins involved in the MAPK and PI3 kinase intracellular signaling pathways. Phosphorylated and total FAK was also analyzed as described in Materials and methods. 

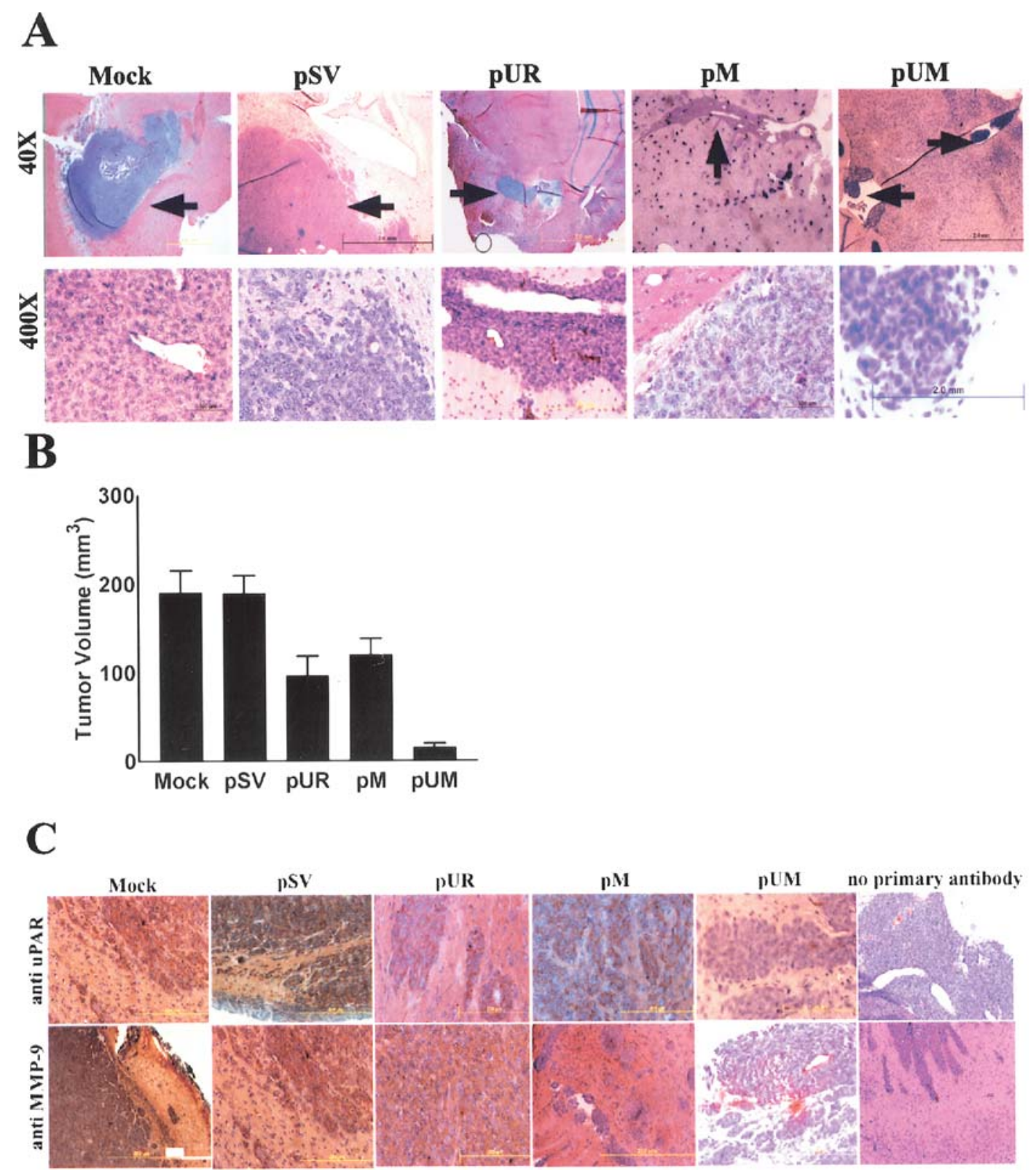

Figure 7. Regression of pre-established orthotopic tumors upon RNAi-mediated downregulation of uPAR and MMP-9. (A) Orthotopic intracranial tumors were established in nude mice and treated with shRNA plasmids as described in Materials and methods. Following extraction, the brains were embedded in paraffin, sectioned and stained with H\&E. Photomicrographs of tumor sections revealing total tumor (x40) and rapidly dividing tumor cells (x400) are shown in the figure. (B) Semi-quantification of tumor volume was performed as described in Materials and methods. Values represent mean \pm SD from five different animals. (C) Immunohistochemical detection for uPAR and MMP-9 expression in pre-established orthotopic tumors following treatment with shRNA plasmids: paraffin-embedded tumor sections were subjected to immunohistochemical detection for uPAR and MMP-9 following standard protocol. Appropriate protein-specific antibodies were used. The slides were stained with hematoxylin to visualize the nucleus, mounted and observed under a light microscope Fields with brown stain resulting from DAB interaction were scored for protein expression.

together, these results show that RNAi-mediated downregulation of UPAR and MMP-9 reduced tumor cell invasion, migration and tumor cell-mediated angiogenesis in vitro. These observations prompted us to evaluate the therapeutic effect of the RNAi-mediated downregulation of UPAR and MMP-9 in an in vivo model.

RNAi-mediated knockdown of UPAR and MMP-9 led to a restorative effect on tumorigenesis in athymic nude mice. Mice with pre-established meningioma growth after one week received SV, pUR, pM, and pUM through alzet mini-osmotic pumps as described previously (30). Brain sections of mice treated with SV or controls showed rapid tumor growth, whereas mice injected with pUM vector using mini-osmotic pumps into a pre-established tumor growth almost completely regressed (Fig. 7A). Quantification of tumor size showed almost complete regression of tumor in the pUM vectortreated group compared to controls and pSV (Fig. 7B). Brain sections of mice in the pUR or pM vector-treated group resulted in $\sim 50 \%$ tumor regression compared to control groups. Furthermore, immunohistochemical analysis for expression of UPAR and MMP-9 in sections derived from pUR-, pMand pUM-treated groups revealed a significant decrease in the expression of proteins as compared to control (mock) or 
pSV-treated brain sections (Fig. 7C). Thus, these results reveal that the RNAi-mediated downregulation of uPAR and MMP-9 has a curative effect on pre-established tumors in vivo.

\section{Discussion}

Meningiomas are the most common type of brain tumors, accounting for $27 \%$ of primary brain tumors and $12 \%$ of all spinal cord tumors. Typically, meningiomas are benign and are effectively treated through surgical resection. However, $10 \%$ of meningiomas do progress to atypical or anaplastic malignant meningiomas, which usually recur even after tumor removal. Thus, these meningiomas pose a therapeutic challenge. Other than surgery, meningiomas are also traditionally treated with radiation therapy. Hormonal therapy is currently under investigation, but has not yet been established. Hence, research efforts are underway for novel treatment approaches.

RNA interference (RNAi) is the phenomenon wherein gene expression is effectively suppressed through the introduction of gene-specific, double-stranded RNA (dsRNA). The phenomenon was first observed in plants, later in the worm caenorhabditis, and subsequent studies have shown that RNAi exists in a wide variety of eukaryotic organisms including mammals $(37,38)$. RNAi was originally believed to work as a defense mechanism against invading viruses, but preliminary studies have shown that it also has a role in maintenance of heterochromatin during mitosis and meiosis. Once the dsRNA is introduced into a cell, it is cleaved by Rnase III such as enzyme Dicer into double-stranded 21-23 nucleotides that are small interfering RNAs (siRNA) with 2 nucleotide overhangs at the 3'-end. Later in an ATP-dependent manner, these siRNA become integrated into a multi-subunit protein complex (RISC) that guides the siRNA to the target (39). The siRNA duplex later unwind; and the anti-sense strand brings degradation of the complementary target mRNA sequence through endonuclease and exonuclease. In recent years, RNAi treatment has proven to have therapeutic benefits in a variety of in vivo disease models $(40,41)$. Since conventional methods used for cancer treatment are known to cause unwanted side effects, the present attempt was made to analyze the feasibility of using RNAi technology for the treatment of malignant meningioma.

Cancer progression is a complex mechanism and depends mainly on the degradation of the extracellular matrix, a task accomplished by various classes of proteinases. Several earlier studies have reported the increased expression of UPAR in various types of cancers $(8,14,42)$ and also its localization and active role at the tumor invasion front $(15,43)$. Furthermore, earlier reports suggested a strong role for uPAR in cell adhesion since UPAR consists of a site for binding to vitronectin (44). Several studies also revealed that UPAR initiates intracellular events and thus contributes to cell proliferation $(45,46)$. Elevated MMP-9 levels have been reported in various cancers (47-50). Studies have reported elevated expression of both UPAR and MMP-9 in human meningiomas (51). In the present study, intracellular administration of gene-specific siRNA targeted against uPAR and MMP-9 plasmids inhibited the protein and mRNA levels of these molecules with pUR-, pM- and pUM-treated groups compared to control and SV-treated cells.

It is well known that the UPA-uPAR plasminolytic system participates not only in proteolysis but also plays an important role in cell proliferation, migration and invasion. The proteolytic system mainly enhances cell proliferation through interaction with extracellular domains of transmembrane proteins such as integrins, EGFR, PDGFR, low-density lipoprotein receptor-related protein, FPRL1 and FPR $(34,52)$. Studies have established that all these receptors actively transfer mitogenic signals from the extracellular environment to cellular machinery. Enhanced expression and active participation of MMP-9 in cell proliferation was observed in mice undergoing hepatic regeneration following partial hepatectomy (53). In accordance with these observations, we report downregulation of UPAR and MMP-9 reduced in vitro proliferation of IOMMLee cells as assessed with the MTT assay. Moreover, cell proliferation decreased significantly in IOMM-Lee cells treated with pUM as compared to cells treated with either pUR or pM (Fig. 3).

Tumor progression occurs through invasion of tumor cells into surrounding normal tissue. This process involves cell-cell, cell-extracellular matrix interactions and actively engages several biochemical processes such as ECM degradation by a variety of proteinases. Migratory ability of tumor cells is also responsible for metastasis, a key process that aids in tumor propagation. Our study revealed that RNAi-mediated downregulation of UPAR and MMP-9 resulted in a decrease in the migration of IOMM-Lee tumor spheroids cultured on a vitronectin-coated substrate. Our results are in agreement with earlier studies that reported the involvement of the uPAuPAR plasminolytic system in tumor migration in glioblastoma cells (54).

Increased expression of uPAR was observed at the leading edge of the tumor in an orthotopic mouse model of osteosarcoma. Furthermore, blocking uPAR expression in the osteosarcoma tumor model using UPAR antisense oligonucleotides resulted in tumor regression and reduction in metastasis (55). Blockage of uPAR expression through urokinase-derived peptides resulted in regression of tumors and metastasis in orthotopic prostate tumors induced in nude mice (56). Several earlier studies have established the role of MMP-9 in extra-cellular matrix degradation and invasion. In human colon cancer, MMP-9 is expressed in excess at the tumor invasion front (57). Angiogenesis is an important feature of malignancy as cancer cells need a rich vascular supply to sustain tumor growth and metastasis (58). Jodele et al (59) reported the role of stromal-derived matrix metalloproteinases in bringing about an interaction between stromal cells and tumor cells in a tumor microenvironment and the positive impact of these interactions on angiogenesis and metastasis in various types of cancer. Increased expression of the components of the plasminolytic system (uPA and uPAR) and their close association with angiogenesis was observed in gastric cancer (14). A balance between its promoters and inhibitors in general regulates angiogenesis. Angiostatin is an angiogenesis inhibitor generated by the membranes of platelets. Inhibition of generation of angiostatin and a subsequent favorable effect on angiogenesis was reported by Jurasz et al (60) in HUVEC cells. 
Our study revealed a remarkable reduction in the invasion and angiogenesis of IOMM-Lee cells following RNAimediated targeting of uPAR and MMP-9, both individually and simultaneously, compared to controls or pSV-treated groups. These observations are in agreement with our previous studies where we downregulated UPAR and MMP-9 in glioblastoma (28) as well as UPA and UPAR in prostate cancer (61) using gene-specific siRNA.

In continuation with these observations, we studied the intracellular signaling pathways for a better understanding of the fundamental molecular processes responsible for the observed effects. Pro-activation of the Ras-ERK pathway by plasminolytic system proteins uPA and UPAR is well documented $(62,63)$. Hypoxia-induced upregulation of uPAR and the associated activation of the MAPK pathway was reported in a human prostate cancer cell line, PC3MLN4 (63). uPAR-induced activation of the MAPK pathway mediated through EGFR resulted in the initiation of mitogenesis (62). Downregulation of uPAR resulted in the loss of uPAR- $\beta 1$ integrin complex and subsequently led to a decrease in ERK signaling in colon cancer cells (16). Differential activation of the MAPK and Akt pathways in response to aggressive phenotype has been observed in different grades of meningioma. This study revealed that MAPK activation is associated with proliferation and apoptosis of malignant meningiomas whereas PI3 kinase/AKT signaling contributes to the aggressive behavior (64). In the present study, we observed a decrease in phosphorylation status of ERK I, ERK II, Akt, mTOR and FAK. Our results are in agreement with Karkoulias et al (65) who reported crosstalk among these pathways and simultaneous upregulation of these pathways upon stimulation.

In recent years, paraclinical investigations into malignant tumors have achieved considerable progress and more comfortable treatments are available, but the life expectancy of patients has not increased significantly. This paradox can be explained in terms of the difficulties encountered in studying the effect of treatments at the cellular and molecular levels in vivo (66). Several earlier studies have revealed that a number of human cancer cell types, when delivered into nude mice through orthotopic implantation, closely imitate their biological behavior in humans. In our study, orthotopic implantation of IOMM-Lee cells into the brains of nude mice resulted in established tumors. We observed a significant regression of these tumors after treatment with pUR, $\mathrm{pM}$ and pUM whereas treatment with pSV did not have any therapeutic effect. The most significant regression of tumors was observed with pUM. The present study supports our earlier reports, which demonstrated an inhibition of meningioma tumors (established through orthotopic implantation of IOMM-Lee cells in nude mice) upon RNAi-mediated downregulation of urokinase plasminogen activator and its receptor (67). We also reported similar observations in breast cancer and glioblastoma $(10,28)$. Recent studies showed that RNAibased gene therapy effectively suppressed virus-induced encephalitis in mice (68).

The proteins targeted in our study, uPAR and MMP-9, play a multifaceted role during tumorigenesis as both proteins are actively involved in invasion, proliferation and angiogenesis. Here, we have shown that post-transcriptional abrogation of
uPAR and MMP-9 gene expression using RNA interference effectively suppressed tumor cell invasion, angiogenesis in vitro and tumor growth in vivo. Our study demonstrates that RNAi treatment is an effective method to analyze various pathways modulated by tumor cells during tumorigenesis as well as a potential treatment strategy for cancer.

\section{Acknowledgements}

The authors thank Shellee Abraham for preparing the manuscript and Diana Meister and Sushma Jasti for manuscript review. We also thank Noorjehan Ali for technical assistance. This research was supported by National Cancer Institute Grant CA 75557, CA 92393, CA 95058, CA 116708, N.I.N.D.S. NS47699 and NS057529, and Caterpillar, Inc., OSF Saint Francis, Inc., Peoria, IL (to J.S.R.).

\section{References}

1. Bianchini F, D'Alessio S, Fibbi G, Del RM and Calorini L: Cytokine-dependent invasiveness in B16 murine melanoma cells: role of uPA system and MMP-9. Oncol Rep 15: 709-714, 2006.

2. Kim TD, Song KS, Li G, Choi H, Park HD, Lim K, Hwang BD and Yoon WH: Activity and expression of urokinase-type plasminogen activator and matrix metalloproteinases in human colorectal cancer. BMC Cancer 6: 211, 2006.

3. Puli S, Lai JC and Bhushan A: Inhibition of matrix degrading enzymes and invasion in human glioblastoma (U87MG) cells by isoflavones. J Neurooncol 79: 135-142, 2006.

4. Schwab W, Schulze-Tanzil G, Mobasheri A, Dressler J, Kotzsch $M$ and Shakibaei M: Interleukin-1beta-induced expression of the urokinase-type plasminogen activator receptor and its co-localization with MMPs in human articular chondrocytes. Histol Histopathol 19: 105-112, 2004.

5. Tan X, Egami H, Nozawa F, Abe M and Baba H: Analysis of the invasion-metastasis mechanism in pancreatic cancer: involvement of plasmin(ogen) cascade proteins in the invasion of pancreatic cancer cells. Int J Oncol 28: 369-374, 2006.

6. Yamashita K, Tanaka Y, Mimori K, Inoue H and Mori M Differential expression of MMP and uPA systems and prognostic relevance of their expression in esophageal squamous cell carcinoma. Int J Cancer 110: 201-207, 2004.

7. Kiian I, Tkachuk N, Haller H and Dumler I: Urokinaseinduced migration of human vascular smooth muscle cells requires coupling of the small GTPases RhoA and Rac1 to the Tyk2/PI3-K signalling pathway. Thromb Haemost 89: 904-914, 2003.

8. Gandhari M, Arens N, Majety M, Dorn-Beineke A and Hildenbrand R: Urokinase-type plasminogen activator induces proliferation in breast cancer cells. Int J Oncol 28: 1463-1470, 2006

9. Castiglioni T, Merino MJ, Elsner B, Lah TT, Sloane BF and Emmert-Buck MR: Immunohistochemical analysis of cathepsins D, B, and L in human breast cancer. Hum Pathol 25: 857-862, 1994.

10. Subramanian R, Gondi CS, Lakka SS, Jutla A and Rao JS: siRNA-mediated simultaneous downregulation of uPA and its receptor inhibits angiogenesis and invasiveness triggering apoptosis in breast cancer cells. Int J Oncol 28: 831-839, 2006.

11. Wang QX, Wang TX, Sun CF and Zhang J: Expressions and clinical significance of urokinase-type plasminogen activator (UPA) and uPA receptor ( $\mathrm{UPAR}$ ) in tongue squamous cell carcinoma. Shanghai Kou Qiang Yi Xue 15: 85-87, 2006.

12. Dass CR, Nadesapillai AP, Robin D, Howard ML, Fisher JL, Zhou $\mathrm{H}$ and Choong PF: Downregulation of uPAR confirms link in growth and metastasis of osteosarcoma. Clin Exp Metastasis 22: 643-652, 2005.

13. Han B, Nakamura M, Zhou G, Ishii A, Nakamura A, Bai Y, Mori I and Kakudo K: Calcitonin inhibits invasion of breast cancer cells: involvement of urokinase-type plasminogen activator (uPA) and UPA receptor. Int J Oncol 28: 807-814, 2006. 
14. Zhang L, Zhao ZS, Ru GQ and Ma J: Correlative studies on uPA mRNA and uPAR mRNA expression with vascular endothelial growth factor, microvessel density, progression and survival time of patients with gastric cancer. World J Gastroenterol 12: 3970-3976, 2006.

15. Wang XQ, Sun P and Paller AS: Gangliosides inhibit urokinasetype plasminogen activator (uPA)-dependent squamous carcinoma cell migration by preventing uPA receptor/alphabeta integrin/ epidermal growth factor receptor interactions. J Invest Dermatol 124: 839-848, 2005.

16. Ahmed N, Oliva K, Wang Y, Quinn M and Rice G: Downregulation of urokinase plasminogen activator receptor expression inhibits Erk signalling with concomitant suppression of invasiveness due to loss of uPAR-betal integrin complex in colon cancer cells. Br J Cancer 89: 374-384, 2003.

17. Ichikawa Y, Ishikawa T, Tanaka K, Togo S and Shimada H: Extracellular matrix degradation enzymes: important factors in liver metastasis of colorectal cancer and good targets for anticancer metastatic therapy. Nippon Geka Gakkai Zasshi 102: 376-380, 2001.

18. Jennbacken K, Gustavsson H, Welen K, Vallbo C and Damber JE: Prostate cancer progression into androgen independency is associated with alterations in cell adhesion and invasivity. Prostate 66: 1631-1640, 2006.

19. Marcellini M, De Luca N, Riccioni T, Ciucci A, Orecchia A, Lacal PM, Ruffini F, Pesce M, Cianfarani F, Zambruno G, Orlandi A and Failla CM: Increased melanoma growth and metastasis spreading in mice overexpressing placenta growth factor. Am J Pathol 169: 643-654, 2006.

20. Nozawa H, Chiu C and Hanahan D: Infiltrating neutrophils mediate the initial angiogenic switch in a mouse model of multistage carcinogenesis. Proc Natl Acad Sci USA 103: 12493-12498, 2006

21. Fahling M, Steege A, Perlewitz A, Nafz B, Mrowka R, Persson PB and Thiele BJ: Role of nucleolin in posttranscriptional control of MMP-9 expression. Biochim Biophys Acta 1731: 32-40, 2005.

22. Taraboletti G, D'Ascenzo S, Giusti I, Marchetti D, Borsotti P, Millimaggi D, Giavazzi R, Pavan A and Dolo V: Bioavailability of VEGF in tumor-shed vesicles depends on vesicle burst induced by acidic $\mathrm{pH}$. Neoplasia 8: 96-103, 2006.

23. Yao C, Roderfeld M, Rath T, Roeb E, Bernhagen J and Steffens G: The impact of proteinase-induced matrix degradation on the release of VEGF from heparinized collagen matrices. Biomaterials 27: 1608-1616, 2006.

24. Meyer E, Vollmer JY, Bovey R and Stamenkovic I: Matrix metalloproteinases 9 and 10 inhibit protein kinase Cpotentiated, p53-mediated apoptosis. Cancer Res 65: 4261$4272,2005$.

25. Kido S, Kitadai Y, Hattori N, Haruma K, Kido T, Ohta M, Tanaka S, Yoshihara M, Sumii K, Ohmoto Y and Chayama K: Interleukin 8 and vascular endothelial growth factor - prognostic factors in human gastric carcinomas? Eur J Cancer 37: 1482-1487, 2001.

26. Rao JS, Yamamoto M, Mohaman S, Gokaslan ZL, Fuller GN, Stetler-Stevenson WG, Rao VH, Liotta LA, Nicolson GL and Sawaya RE: Expression and localization of $92 \mathrm{kDa}$ type IV collagenase/gelatinase B (MMP-9) in human gliomas. Clin Exp Metastasis 14: 12-18, 1996.

27. Rao JS, Gondi CS, Chittivelu S, Joseph PA and Lakka SS: Inhibition of invasion, angiogenesis, tumor growth and metastasis by adenovirus-mediated transfer of antisense UPAR and MMP-9 in non-small cell lung cancer cells. Mol Cancer Ther 4: 1399-1408, 2005.

28. Lakka SS, Gondi CS, Dinh DH, Olivero WC, Gujrati M, Rao VH, Sioka C and Rao JS: Specific interference of uPAR and MMP-9 gene expression induced by double-stranded RNA results in decreased invasion, tumor growth and angiogenesis in gliomas. J Biol Chem 280: 21882-21892, 2005.

29. Gregory RI, Chendrimada TP and Shiekhattar R: MicroRNA biogenesis: isolation and characterization of the microprocessor complex. Methods Mol Biol 342: 33-47, 2006.

30. Lakka SS, Gondi CS, Yanamandra N, Olivero WC, Dinh DH, Gujrati M and Rao JS: Inhibition of cathepsin B and MMP-9 gene expression in glioblastoma cell line via RNA interference reduces tumor cell invasion, tumor growth and angiogenesis. Oncogene 23: 4681-4689, 2004.

31. Wang FQ, So J, Reierstad S and Fishman DA: Matrilysin (MMP-7) promotes invasion of ovarian cancer cells by activation of progelatinase. Int J Cancer 114: 19-31, 2005.
32. Leunig M, Yuan F, Menger MD, Boucher Y, Goetz AE, Messmer K and Jain RK: Angiogenesis, microvascular architecture, microhemodynamics and interstitial fluid pressure during early growth of human adenocarcinoma LS174T in SCID mice. Cancer Res 52: 6553-6560, 1992.

33. Brockmann MA, Westphal M and Lamszus K: Improved method for the intracerebral engraftment of tumour cells and intratumoural treatment using a guide screw system in mice. Acta Neurochir 145: 777-781, 2003.

34. Kiyan J, Kiyan R, Haller H and Dumler I: Urokinase-induced signaling in human vascular smooth muscle cells is mediated by PDGFR-beta. EMBO J 24: 1787-1797, 2005.

35. Roomi MW, Ivanov V, Kalinovsky T, Niedzwiecki A and Rath M: Inhibition of malignant mesothelioma cell matrix metalloproteinase production and invasion by a novel nutrient mixture. Exp Lung Res 32: 69-79, 2006.

36. Browaeys-Poly E, Cailliau K and Vilain JP: Transduction cascades initiated by fibroblast growth factor 1 on Xenopus oocytes expressing MDA-MB-231 mRNAs. Role of Grb2, phosphatidylinositol 3-kinase, Src tyrosine kinase and phospholipase Cgamma. Cell Signal 13: 363-368, 2001.

37. Fire A, Xu S, Montgomery MK, Kostas SA, Driver SE and Mello CC: Potent and specific genetic interference by doublestranded RNA in Caenorhabditis elegans. Nature 391: 806-811, 1998

38. Napoli C, Lemieux C and Jorgensen R: Introduction of a chimeric chalcone synthase gene into petunia results in reversible cosuppression of homologous genes in trans. Plant Cell 2: 279-289, 1990

39. Elbashir SM, Harborth J, Lendeckel W, Yalcin A, Weber K and Tuschl T: Duplexes of 21-nucleotide RNAs mediate RNA interference in cultured mammalian cells. Nature 411: 494-498, 2001

40. Morris KV, Chan SW, Jacobsen SE and Looney DJ: Small interfering RNA-induced transcriptional gene silencing in human cells. Science 305: 1289-1292, 2004.

41. Soutschek J, Akinc A, Bramlage B, Charisse K, Constien R, Donoghue M, Elbashir S, Geick A, Hadwiger P, Harborth J, John M, Kesavan V, Lavine G, Pandey RK, Racie T, Rajeev KG, Rohl I, Toudjarska I, Wang G, Wuschko S, Bumcrot D, Koteliansky V, Limmer S, Manoharan M and Vornlocher HP: Therapeutic silencing of an endogenous gene by systemic administration of modified siRNAs. Nature 432: 173-178, 2004.

42. Park J, Song SH, Kim TY, Choi MC, Jong HS, Kim TY, Lee JW, Kim NK, Kim WH and Bang YJ: Aberrant methylation of integrin alpha4 gene in human gastric cancer cells. Oncogene 23: 3474-3480, 2004

43. Van der Pluijm G, Sijmons B, Vloedgraven H, van der Bent C Drijfhout JW, Verheijen J, Quax P, Karperien M, Papapoulos S and Lowik C: Urokinase-receptor/integrin complexes are functionally involved in adhesion and progression of human breast cancer in vivo. Am J Pathol 159: 971-982, 2001.

44. Vial D, Monaghan-Benson E and Keown-Longo PJ: Coordinate regulation of fibronectin matrix assembly by the plasminogen activator system and vitronectin in human osteosarcoma cells. Cancer Cell Int 6: 8, 2006.

45. Adachi Y, Lakka SS, Chandrasekar N, Yanamandra N, Gondi CS, Mohanam S, Dinh DH, Olivero WC, Gujrati M, Tamiya T, Ohmoto T, Kouraklis G, Aggarwal B and Rao JS: Downregulation of integrin alpha(v)beta(3) expression and integrinmediated signaling in glioma cells by adenovirus-mediated transfer of antisense urokinase-type plasminogen activator receptor ( $\mathrm{uPAR}$ ) and sense p16 genes. J Biol Chem 276: 47171-47177, 2001.

46. Aguirre-Ghiso JA: Inhibition of FAK signaling activated by urokinase receptor induces dormancy in human carcinoma cells in vivo. Oncogene 21: 2513-2524, 2002.

47. Fernandez CA, Yan L, Louis G, Yang J, Kutok JL and Moses MA The matrix metalloproteinase-9/neutrophil gelatinase-associated lipocalin complex plays a role in breast tumor growth and is present in the urine of breast cancer patients. Clin Cancer Res 11: 5390-5395, 2005

48. Gong YL, Xu GM, Huang WD and Chen LB: Expression of matrix metalloproteinases and the tissue inhibitors of metalloproteinases and their local invasiveness and metastasis in Chinese human pancreatic cancer. J Surg Oncol 73: 95-99, 2000.

49. Iizasa T, Fujisawa T, Suzuki M, Motohashi S, Yasufuku K, Yasukawa T, Baba M and Shiba M: Elevated levels of circulating plasma matrix metalloproteinase 9 in non-small cell lung cancer patients. Clin Cancer Res 5: 149-153, 1999. 
50. Pereira AM, Strasberg-Rieber M and Rieber M: Invasionassociated MMP-2 and MMP-9 are up-regulated intracellularly in concert with apoptosis linked to melanoma cell detachment. Clin Exp Metastasis 22: 285-295, 2005.

51. Siddique K, Yanamandra N, Gujrati M, Dinh D, Rao JS and Olivero W: Expression of matrix metalloproteinases, their inhibitors, and urokinase plasminogen activator in human meningiomas. Int J Oncol 22: 289-294, 2003.

52. Selleri C, Montuori N, Ricci P, Visconte V, Carriero MV, Sidenius N, Serio B, Blasi F, Rotoli B, Rossi G and Ragno P: Involvement of the urokinase-type plasminogen activator receptor in hematopoietic stem cell mobilization. Blood 105: 2198-2205, 2005.

53. Olle EW, Ren X, McClintock SD, Warner RL, Deogracias MP, Johnson KJ and Colletti LM: Matrix metalloproteinase-9 is an important factor in hepatic regeneration after partial hepatectomy in mice. Hepatology 44: 540-549, 2006.

54. Lamy S, Lafleur R, Bedard V, Moghrabi A, Barrette S, Gingras D and Beliveau R: Anthocyanidins inhibit migration of glioblastoma cells: structure-activity relationship and involvement of the plasminolytic system. J Cell Biochem (In press).

55. Dass CR and Choong PF: Biophysical delivery of peptides: applicability for cancer therapy. Peptides 27: 3479-3488, 2006.

56. Boyd DD, Kim SJ, Wang H, Jones TR and Gallick GE: A urokinase-derived peptide (A6) increases survival of mice bearing orthotopically grown prostate cancer and reduces lymph node metastasis. Am J Pathol 162: 619-626, 2003.

57. Illemann M, Bird N, Majeed A, Sehested M, Laerum OD, Lund LR, Dano K and Nielsen BS: MMP-9 is differentially expressed in primary human colorectal adenocarcinomas and their metastases. Mol Cancer Res 4: 293-302, 2006.

58. Giatromanolaki A, Sivridis E, Simopoulos C, Polychronidis A, Gatter KC, Harris AL and Koukourakis MI: Hypoxia inducible factors 1alpha and 2alpha are associated with VEGF expression and angiogenesis in gallbladder carcinomas. J Surg Oncol 94: 242-247, 2006.

59. Jodele S, Blavier L, Yoon JM and De Clerck YA: Modifying the soil to affect the seed: role of stromal-derived matrix metalloproteinases in cancer progression. Cancer Metastasis Rev 25: $35-43,2006$
60. Jurasz P, Santos-Martinez MJ, Radomska A and Radomski MW: Generation of platelet angiostatin mediated by urokinase plasminogen activator: effects on angiogenesis. J Thromb Haemost 4: 1095-1106, 2006.

61. Pulukuri SM, Gondi CS, Lakka SS, Jutla A, Estes N, Gujrati M and Rao JS: RNA interference-directed knockdown of urokinase plasminogen activator and urokinase plasminogen activator receptor inhibits prostate cancer cell invasion, survival and tumorigenicity in vivo. J Biol Chem 280: 36529-36540, 2005.

62. Jo M, Thomas KS, Marozkina N, Amin TJ, Silva CM, Parsons SJ and Gonias SL: Dynamic assembly of the urokinase-type plasminogen activator signaling receptor complex determines the mitogenic activity of urokinase-type plasminogen activator. J Biol Chem 280: 17449-17457, 2005 .

63. Lee KH, Choi EY, Hyun MS and Kim JR: Involvement of MAPK pathway in hypoxia-induced up-regulation of urokinase plasminogen activator receptor in a human prostatic cancer cell line, PC3MLN4. Exp Mol Med 36: 57-64, 2004.

64. Mawrin C, Sasse T, Kirches E, Kropf S, Schneider T, Grimm C, Pambor C, Vorwerk CK, Firsching R, Lendeckel U and Dietzmann K: Different activation of mitogen-activated protein kinase and Akt signaling is associated with aggressive phenotype of human meningiomas. Clin Cancer Res 11: 4074-4082, 2005.

65. Karkoulias G, Mastrogianni O, Lymperopoulos A, Paris H and Flordellis C: alpha(2)-adrenergic receptors activate MAPK and Akt through a pathway involving arachidonic acid metabolism by cytochrome P450-dependent epoxygenase, matrix metalloproteinase activation and subtype-specific transactivation of EGFR. Cell Signal 18: 729-739, 2006

66. Taillandier L, Antunes L and Ngioi-Duprez KS: Models for neuro-oncological preclinical studies: solid orthotopic and heterotopic grafts of human gliomas into nude mice. J Neurosci Methods 125: 147-157, 2003.

67. Kondraganti S, Gondi CS, McCutcheon I, Dinh DH, Gujrati M, Rao JS and Olivero W: RNAi-mediated downregulation of urokinase plasminogen activator and its receptor in human meningioma cells inhibits tumor invasion and growth. Int J Oncol 28: 1353-1360, 2006.

68. Kumar P, Lee SK, Shankar P and Manjunath N: A single siRNA suppresses fatal encephalitis induced by two different flaviviruses. PLoS Med 3: e96, 2006. 